Environment Conservation Journal 20 (1\&2) 81-86, 2019

ISSN 0972-3099 (Print) 2278-5124 (Online)

Abstracted and Indexed

\title{
Localization of Cadmium metal ion in Lemna polyrhiza L. using SEM morphology and EDX analysis
}

\author{
Unadkat K. and Parikh P.
}

Received: 25.08 .2018

Revised: 28.12 .2018

Accepted: 14.03.2019

\begin{abstract}
Cadmium is considered to be one of the most toxic metals even at lower concentration. The significance of toxic concentration of cadmium provided individually was investigated in order to assess the effect of metal interaction in Lemna polyrhiza $L$. The objective of the present study was to evaluate the effect of Cadmium (Cd) ion and possible variations in its tissue after 6 days exposure to $0.5 \mathrm{ppm}$ Cd solution. Lemna polyrhiza $L$. was cultured in hoagland medium supplemented with $0.5 \mathrm{ppm} C d$ concentration and harvested after 6 day. To scrutinize anatomical abnormalities SEMEDX analysis were carried out for cadmium treated plants $(0.5 \mathrm{ppm})$ for both the test and control plants. Surface morphology of control plant showed non shiny, porous, non crystalline surface with fixed shape and was found to maintain evenness throughout the surface where as SEM images of cadmium treated samples revealed shiny, crystalline and white surface which is evidence that cadmium have got absorbed on the surface. Furthermore, more porous nature of control samples was the indications of the plant to be a good bioindicator of cadmium contaminated environment. The results obtained inveterate that Lemna polyrhiza $L$. is heavy metal accumulator and thus SEM-EDX applications in natural habitat open up broad prospects for future studies of metal ecotoxicity.
\end{abstract}

Key Words: Cadmium, SEM-EDX Analysis, Ecotoxicity, Bioindicator, Lemna polyrhiza L.

\section{Introduction}

Plants have been known to accumulate essential metal ions as well as non essential metal ions that are toxic to soil and water. Uptake of excess metal in plants initiates a variety of metabolic reactions, finally leading to global phytotoxic responses such as chlorosis, reduction of growth, especially root growth and disturbance in carbohydrate metabolism ${ }^{5}$. Heavy metals at high concentration in substrate when taken up by the plants develop toxic characters, which becomes expressed with anatomical alteration or even malformations (Unadkat and Parikh, 2012). At ultrastructural level, effect of cadmium includes swelling of cells and mitochondrial vacuolation followed by its degeneration (Silverberg, 1976.), disruption of cell separation, formation of cell clumps as well as elongated bend cells and break down of cortex (Sridhar et al., 2007). Moreover, cadmium tolerance mechanisms may differ depending on the species because of the amount of Cadmium

\section{Author's Address}

Department of Botany, Faculty of Science, the Maharaja Sayajirao University of Baroda, Vadodara.

E-mail.: unadkatkrupa@yahoo.co.in retained in active site can be small,then its toxicity is alleviated (Cobbett, 2000). The use of aquatic macrophytes such as water hyacinth (Baruah et al., 2012) Vallisneria (Sahar et al., 2017) and water hyacinth (Lu et al., 2004) in wastewater treatment has engrossed global awareness in recent years. Water hyacinth is also known as beautiful devil because of its adverse impact on the water bodies Lemna polyrhiza $L$. is a free floating macrophyte and very common plant found in ponds, ditches and shallow water. However, they reproduce easily and during rainy season, these plants pose threat to river due to clogging drains. It is reported to grow in effluents of various industries and thus can be explored to clean up various metal contaminated sites. In this context, to establish changes in morphology and elemental position of control and Cd treated plants of L. polyrhiza L., we have performed SEM-EDX analysis as SEM has proved to be a powerful technique that can be used to investigate metal bindings to biomolecules (Moya et al., 1993). 


\section{Materials and Methods Experimental Setup:}

For the experiment, 7-8 weeks old Lemna polyrhiza L. with approximately same size and weight, were collected from Harni pond, Vadodara (Fig 1 and Fig 2). The plants were washed thoroughly with tap water followed by de-ionized water prior to the experimentation. All the plants were grown in modified Hoagland's nutrient solution.

\section{Heavy metal preparation}

All experimental work was done using deionised water, and all reagents were of analytical grade. $\mathrm{Cd}$ stock solution was prepared at $1000 \mathrm{ppm}$ which was later diluted as required. Lemna polyrhiza $\mathrm{L}$ were acclimatized in the laboratory condition, and subjected to a solution of $\mathrm{Cd}$ of concentration 0.1 , $0.2,0.3,0.4$ and $0.5 \mathrm{ppm}$.

Scanning Electron microscopy (SEM) and energy dispersive $X$ - ray (EDX) Studies:

For the surface morphology determination of control and cadmium treated plants, SEM analysis and to determine elemental composition, SEMEDX were performed. The fine sample was dried in oven at $105^{\circ} \mathrm{C}$ for 24 hours. Then, the samples were analyzed by SEM instrument (JEOL Japan-6490). EDX was also analyzed by EDS (EDS-133) instrument.

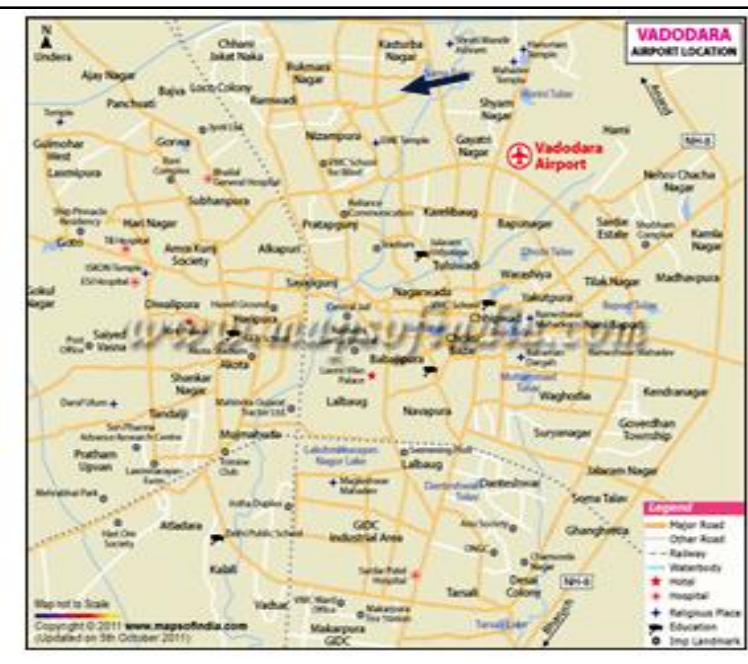

Fig. 1 Map of Vadodara

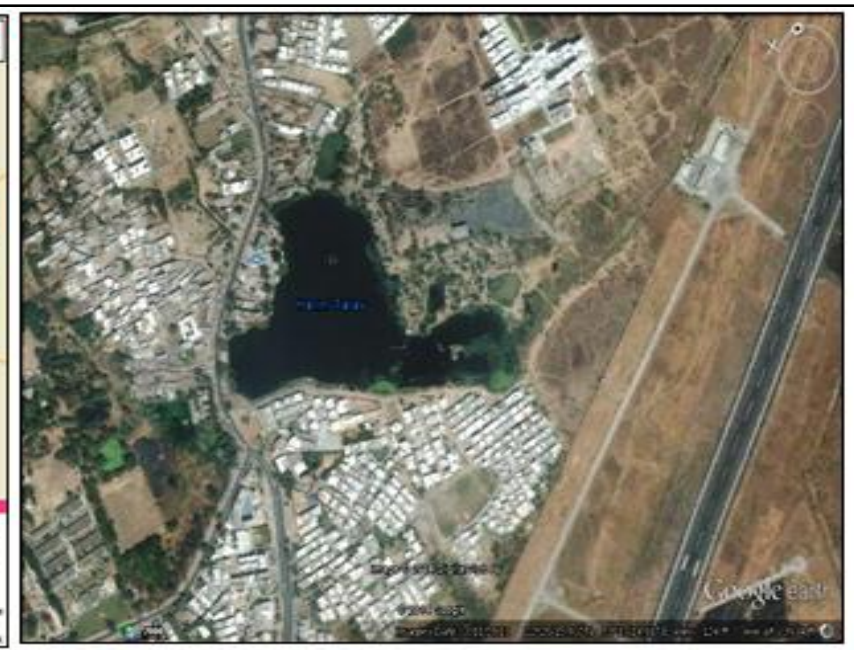

Fig. 2 Google Map image of Harni pond

\section{Results and Discussion SEM EDX Analysis:}

In the present research, SEM analysis was conducted to observe the surface morphology of $L$. polyrhiza L. plant powder before (control samples) and after biosorption of cadmium (treated samples). The results on SEM analysis confide the variation in the ultrastructure of control and $\mathrm{Cd}$ treated cells of $L$. polyrhiza L. The SEM images of control plant samples with magnifying $1000 \mathrm{X}$ were showed to have porous, dense and heterogenous rough surface. This indicated that $L$. polyrhiza $\mathrm{L}$. have good possibilities as biosorbent of metal ion (Fig. 3 and 4 A1, A2). When L.polyrhhiza L. was treated with $0.5 \mathrm{ppm}$ solution of $\mathrm{Cd}$ ion, much anatomical disorganization was observed. In SEM micrograph of treated samples, shiny and white surface morphology indicated the adsorption of $\mathrm{Cd}$ ion on the surface. Also, the surface of treated plant seemed to be complex along with agglomeration of particles on it. It also revealed the combination of small sized and crystalline particles which suggested it to be an appropriate structure for metal ion concentration. The observed crystalline depositions on the cell surface of treated samples might be an indicative of sequestration by specific molecules like metallothioneins (Fig. 3 and 4 B1, B2). It is clear that sublethal concentrations of cadmium caused alterations in surface structure of the experimental plants. Such ultrastructural aberrations occurring in $L$. polyrhhiza $L$. exposed to $\mathrm{Cd}$, at the cellular level might be due to alterations caused by cadmium metal ion. There are several reports in which SEM can be used to 


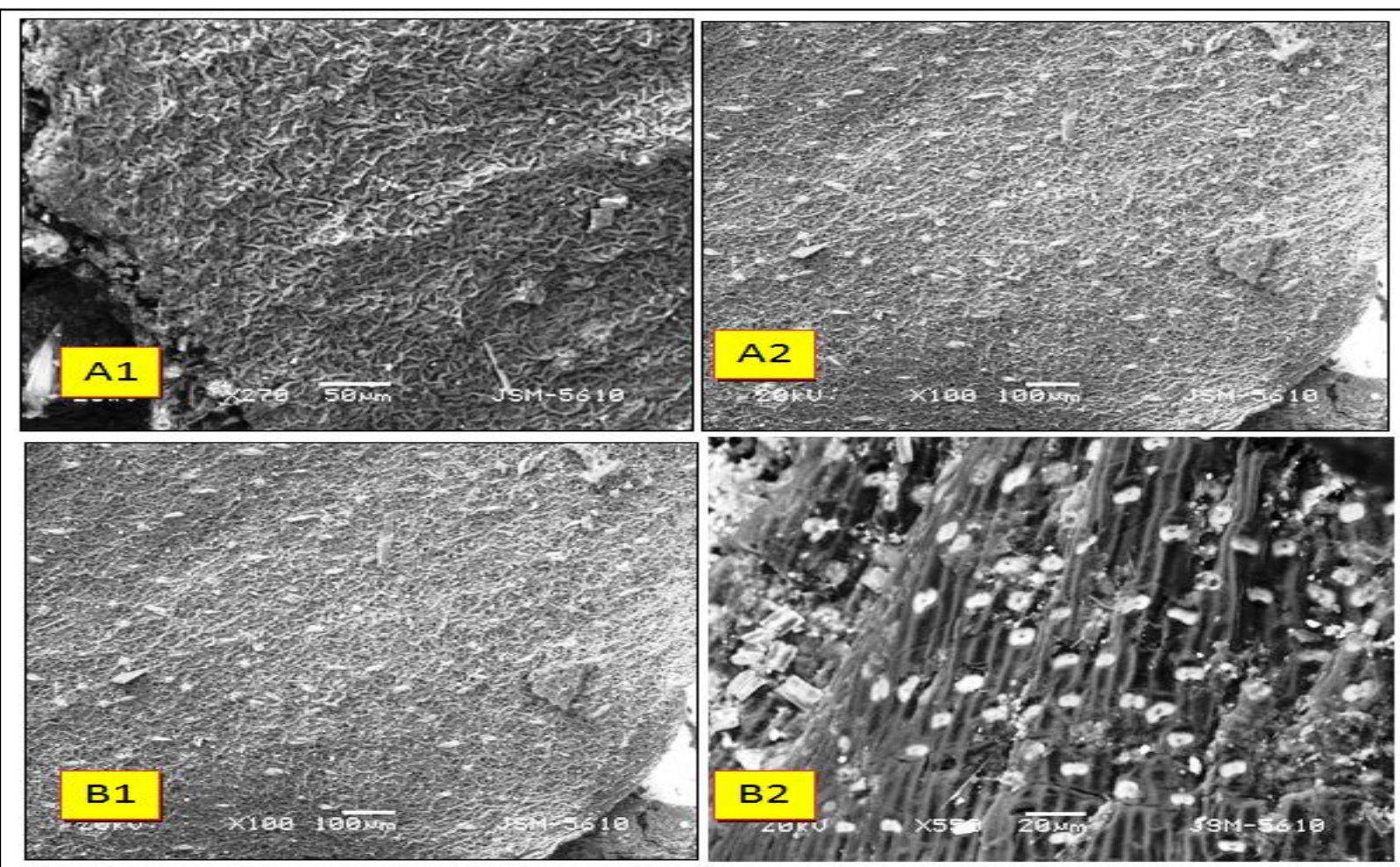

Fig 3. A1 and A2 SEMI Images of control plant and B1 and B2 SEMI Images of Cd treated plant after 6 days of exposure period

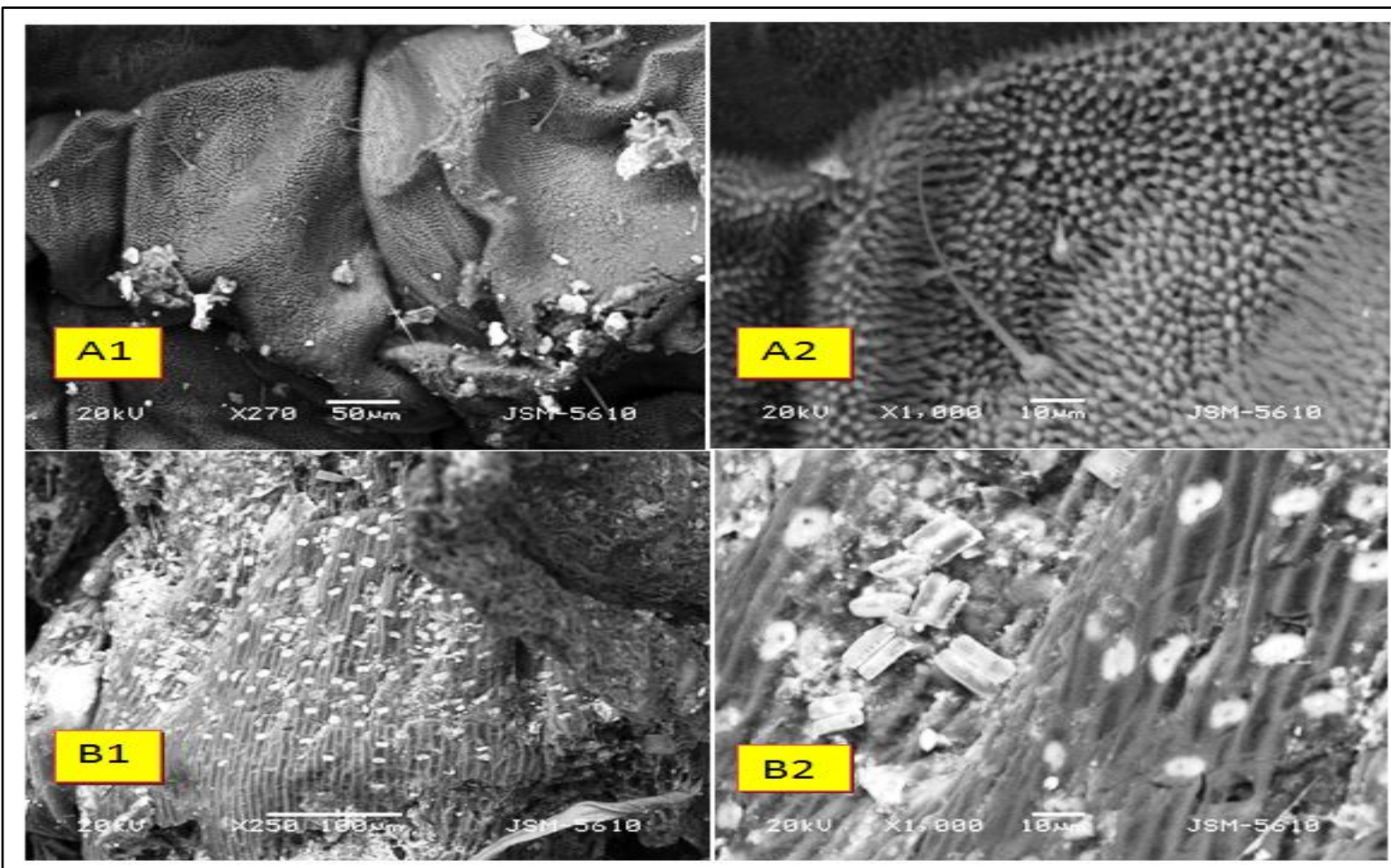

Fig 4. Al and A2 SEMI Images of control plant and B1 and B2 SEMI Images of Cd treated plant after 6 days of exposure period 
visualize the surface morphology of the plant are $56.72 \%$ and $31.49 \%$ respectively. The before and after metal binding, allowing for direct spectrum also showed the presence of magnesium observation of any change. The effect of metal $0.52 \%$, aluminium $1.55 \%$, silicon $0.39 \%$, binding to Sargassum vulgaris using combined phosphorous $0.65 \%$, sulphur 0.34 , chlorine $1.43 \%$, SEM with EDX. SEM analysis revealed that there were significant morphological changes, including shrinking and layer sticking in the sea weed after metal binding (Raize et al., 2004). EDX analysis was performed in the present study to determine the elemental composition of the biosorbents before and after $\mathrm{Cd}$ ion adsorption. The quantitative analysis using EDX of control plant showed that carbon and oxygen are the major constituents that potassium $2.64 \%$, calcium $2.29 \%$, copper $1.99 \%$. Cd not found in control plant. All the metal clearly showed peak while Cd peak did not occur in control plant samples (Figure 5).

The quantitative analysis using EDX of treated plant showed that carbon and oxygen is the major constituents that are $50.50 \%$ and $39.87 \%$ respectively in the biosorbents

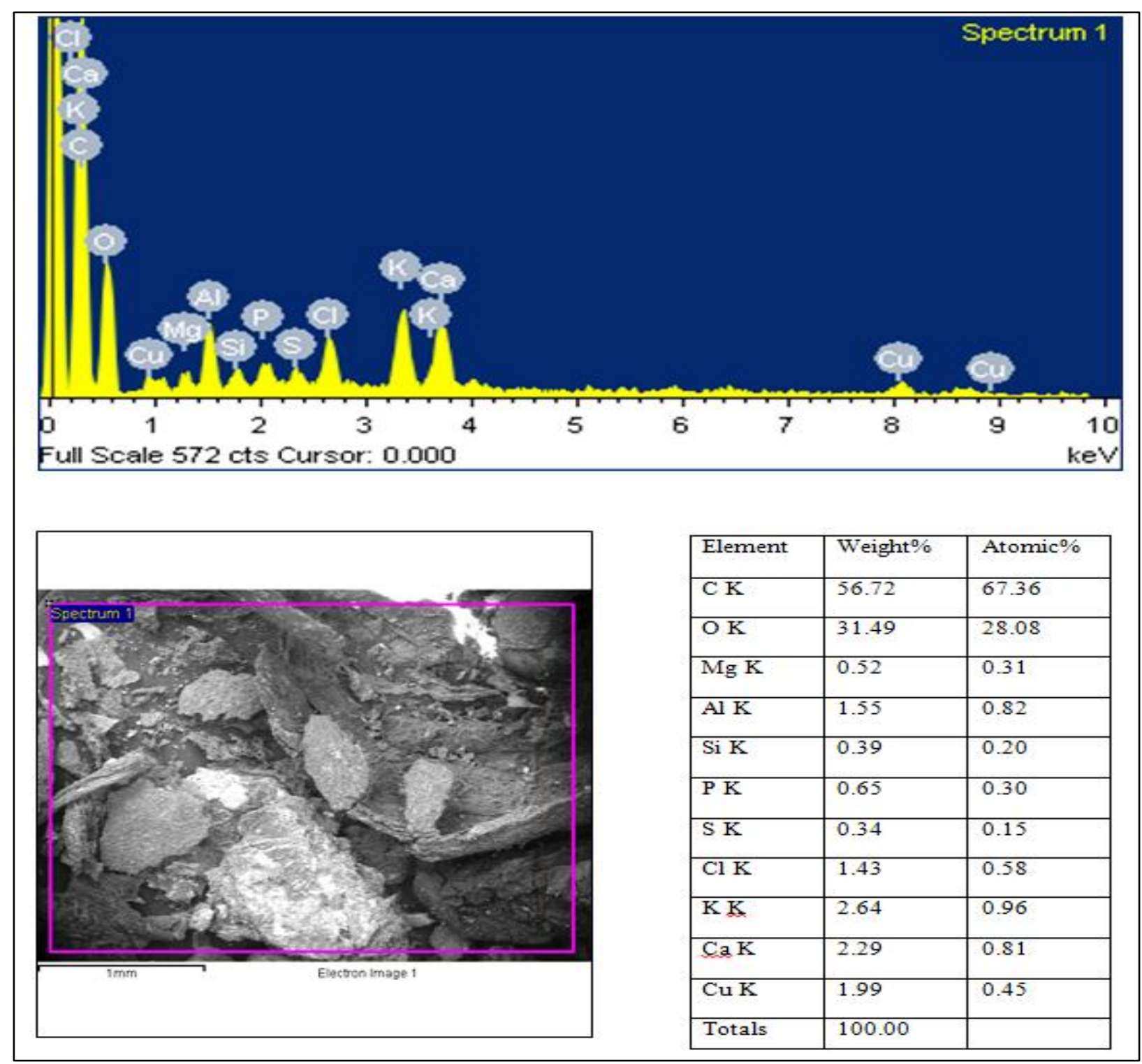

Figure 5. EDX of Control L. polyrhiza $L$. 


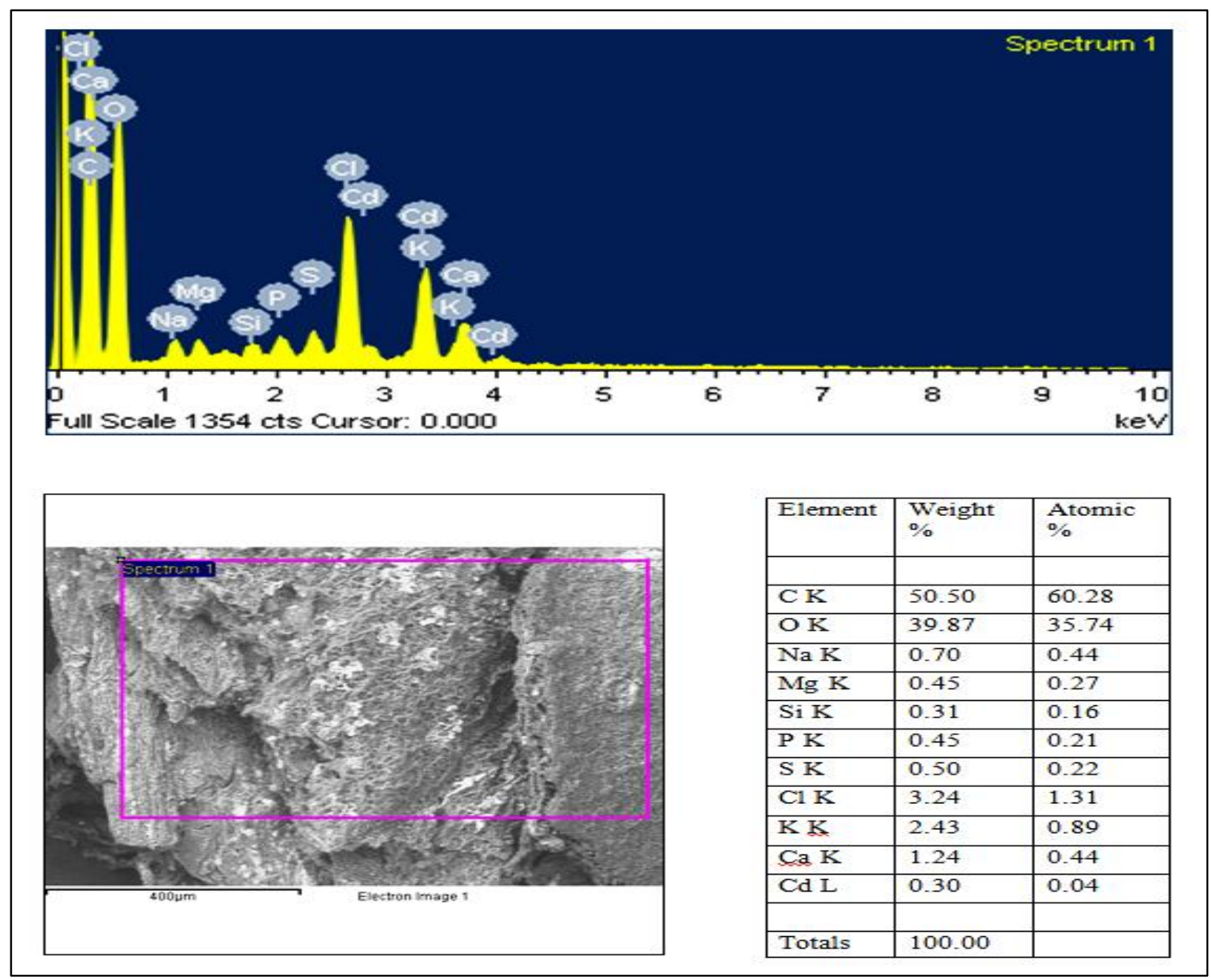

Figure 6. EDX of treated L. polyrhiza $L$.

The spectrum also showed the presence of magnesium $0.45 \%$, Aluminium $1.55 \%$, Silicon $0.31 \%$, Phosphorous $0.45 \%$, Sulphur 0.50, chlorine $3.24 \%$, Potassium $2.43 \%$, Calcium $1.24 \%$, and Copper $1.99 \%$. Cadmium with concentration of $0.30 \%$ found. This indicates that treated plant might have absorbed $\mathrm{Cd}$.This was again confirmed by peak of $\mathrm{Cd}$ in the treated samples (Figure 6).

In addition to that percentage showed that constituent of Carbon, Phosphorous, Sulphur, Chlorine concentrations increased while Oxygen, Silicon, Calcium concentration decreased in treated samples than in control. So, this result revealed that absorption of $\mathrm{Cd}$ also affects the absorption of other metal ions (Jing et al., 2015). The uptake and localization of lead $(\mathrm{Pb})$ within and around root, petiole and leaf of Echhornia crassipes grown hydroponically in a $\mathrm{Pb}\left(\mathrm{NO}_{3}\right)_{2}$ solution using scanning electron microscopy (SEM) coupled with elemental energy dispersive X- Ray microanalysis (EDX) at various increasing concentrations of $\mathrm{Pb}$. Analysis by SEM - EDX showed upward $\mathrm{Pb}$ transport by root vascular tissues to leaf while absence of $\mathrm{Pb}$ in control plant. He elucidates important changes in surface morphology of root and metal binding mechanism using SEM-EDX (Baruah et al., 2012). In Lead (Pb) treated plants of Tectona grandis L. at an intensity of $20 \mathrm{k}$ found characteristic peak of lead inside the leaf and root indicating that $\mathrm{Pb}$ had accumulated in higher proportion on the root surface, but was found decreasing in concentration towards the centre (Sandalio et al., 2001 ). He also observed that $\mathrm{Cd}$ loaded leaf powder has a tendency to form agglomerates. Our results were similar to Zulfi et al., 2013, who worked on effect of $\mathrm{Cu}$ (II) on 
Annona muricata $L$ leaves and their results showed that SEM images of the leaves had porous surface which indicated that it has good potential as biosorbent.

\section{Conclusion}

The SEM micrographs obtained in the present study discovered significant changes in the surface morphological features between control and treated plant samples. SEM combined with EDX technique applied in this research had provided valuable input

\section{References}

Baruah, S., Hazarika, K. and Sarma, K. P. 2012. Uptake and localization of lead in Eichhornia crassipes grown within a hydroponic system. Advance in Applied Science Research, 3(1): 51-59.

Cobbett, C. S. 2000. Phytochelatins and Their Roles in Heavy Metal Detoxification. Plant Physiolog. 123: 825-832.

Jing, L., Yu, H., and Luan, Y. 2015. Meta- analysis of the copper, zinc and cadmium absorption capacities of aquatic plants in heavy metal polluted water. Int. Jr. Environ. Res. Public Health, 12(2): 14958 - 14973.

Lu, X., Kruatrachue ,M., Pokethitiyook, P. 2004. Removal of cadmium and zinc by water hyacinth, Echhornia crassipes, Science Asia. 30: 93-103.

Moya, J. L., Ros, R., and Picazo, I. 1993. Influence of cadmium and nickel on growth, net photosynthesis and carbohydrate distribution in rice plants. Photosyntthesis Research., 36: 75-80.

Raize, O., Argaman, Y. and Yannai, S. 2004. Mechanisms of biosorption of different heavy metals by brown marine macroalgae. Biotechnol Bioeng, 87: 451-458. in determining the distribution of various elements over the surface of Lemna polyrhiza $\mathrm{L}$.

\section{Acknowledgement}

The authors acknowledged the support to Head of Department, Botany, The M.S. University of Vadodara, Vadodara, and Gujarat (INDIA) for providing infrastructure to work, laboratory instruments and necessary facilities.

Sahar, A., Malik, A. and Kezan, O. 2017. The effect of some heavy metals accumulation on anatomical and physiological characteristic of the submerged macrophyte Vallisneria plant. Int. Jr. of Advances in Sci Eng. And Tech., 5(1): 131-135.

Sandalio, L. M.; Dalurzo, H. C., Gómes, M. 2001. RomeroPuertas, M.C. and Del Rio, L.A. Cadmium-induced changes in the growth and oxidative metabolism of pea plants. Journal of Experimental Botany, 52: 2115-2126.

Silverberg, B. A. 1976. Cadmium-induced ultrastructural changes in mitochondria of freshwater green algae. Phycologia., 15: 155-159.

Sridhar, B., Han, F., Diehl, S., Monts, D., and Su, Y. 2007. Effects in $\mathrm{Zn}$ and $\mathrm{Cd}$ accumulation on structural and physiological characteristics of barley plants. Brailian Journal of Plant Physiology, 19(1): 15 - 22.

Unadkat, K. and Parikh, P. 2012. Effect of Nickel onion on stem of Hydrilla verticillata L. Environment Conservation Journal, 13 (1\&2): 107-110.

Zulfi, A., Melia, K., Zein, R., Aziz, H. and Munaf, E. 2013. Prediction of $\mathrm{Pb}$ (II) and $\mathrm{Cu}$ (II) Ions Biosorption by Annona muricata L. Seeds Using Artificial Neural Network (ANN) Approach. Research Journal of Pharmaceutical, Biological and Chemical science, 4(4): 1443-1451. 